\title{
LOH 19q indicates shorter disease progression-free interval in low-grade oligodendrogliomas with EMP3 methylation
}

\author{
ALICE PASINI $^{1-3^{*}}$, PAOLO IORIO ${ }^{4,5^{*}}$, EMANUELA BIANCHI ${ }^{4,6}$, SERENELLA CERASOLI $^{4,5,7}$, \\ ANNA M. CREMONINI ${ }^{4,8}$, MARINA FAEDI $^{4,6}$, CARLO GUARNIERI $^{3}$, GRAZIANO GUIDUCCI $^{4,8}$, \\ LUCA RICCIONI $^{4,7}$, CHIARA MOLINARI ${ }^{9}$, CLAUDIA RENGUCCI ${ }^{9}$, \\ DANIELE CALISTRI $^{9}$ and EMANUELE GIORDANO ${ }^{1-3}$ \\ ${ }^{1}$ Laboratory of Cellular and Molecular Engineering 'S. Cavalcanti', ${ }^{2}$ School of Engineering, \\ Biomedical Engineering, University of Bologna, Cesena; ${ }^{3}$ Department of Biochemistry 'G. Moruzzi', \\ University of Bologna, Bologna; ${ }^{4}$ Gruppo Neuroncologico Romagnolo (GNR), Cesena; ${ }^{5}$ Clinical Pathology Unit, \\ ${ }^{6}$ Oncology Unit, ${ }^{7}$ Pathology Unit, and ${ }^{8}$ Neurosurgery Unit, 'M. Bufalini' Hospital, Cesena; \\ ${ }^{9}$ IRCCS Romagnolo Scientific Institute for the Study and Treatment of Cancer (IRST), Meldola, Italy
}

Received June 15, 2012; Accepted August 3, 2012

DOI: $10.3892 / o r .2012 .2047$

\begin{abstract}
We previously described a cohort of grade II oligodendroglioma (OII) patients, in whom the loss of heterozygosity (LOH) $19 \mathrm{q}$ was present in the subgroup at a higher risk of relapse. In this study, we evaluated the CpG methylation of the putative tumor suppressor epithelial membrane protein 3 $(E M P 3,19 \mathrm{q} 13.3)$ gene promoter in the same OII cohort, to investigate whether a correlation could be found between $E M P 3$ cytogenetic and epigenetic loss and higher risk of relapse. Twenty-three tumor samples from OII patients were collected over a period of 10 years. Seventeen glioblastoma (GBM) samples (2 of which were relapses) were collected from 15 patients. The EMP3, $\mathrm{O}^{6}$-methylguanine methyltransferase $(M G M T)$ and cyclooxygenase 2 (COX2) promoter methylation, evaluated by methylation-specific PCR, and the isocitrate dehydrogenase 1 (IDHI) mutation, identified by sequencing, were compared between the OII and GBM histotypes. The $E M P 3$ promoter methylation was correlated with the analysis of LOH 19q, performed by microsatellite amplification, in OII patients. Disease progression-free interval was evaluated in the OII patients with the EMP3 methylation with either LOH 19q or conserved chromosome 19 arms. The EMP3 and MGMT promoter methylation was more frequent in OII than in GBM patients, and the IDH1 mutation was absent in GBM. The COX2 promoter was unmethylated in both histotypes. Both $\mathrm{LOH}^{+/-} 19 q$
\end{abstract}

Correspondence to: Dr Alice Pasini, Laboratory of Cellular and Molecular Engineering 'S. Cavalcanti', University of Bologna, via Venezia 52, I-47521 Cesena (FC), Italy

E-mail: alice.pasini@unibo.it

*Contributed equally

Key words: disease progression-free interval, epithelial membrane protein 3, gene promoter methylation, loss of heterozygosity, low-grade oligodendroglioma
OII patients showed EMP3 hypermethylation. Concomitant LOH 19q and EMP3 gene promoter methylation was observed in the OII patients at a higher risk of relapse. Our results suggest that a total (cytogenetic and epigenetic) functional loss of both $E M P 3$ alleles accounts for the reduced disease progression-free interval in OII patients. Although the small sample size limits the strength of this study, our results support testing this hypothesis in larger cohorts of patients, considering the methylation of the EMP3 gene promoter together with $\mathrm{LOH} 19 \mathrm{q}$ as an indication for treatment with adjuvant therapy ab initio in order to improve the overall survival of OII patients.

\section{Introduction}

Oligodendrogliomas (ODGs) are classified by the World Health Organization (WHO) as low-grade gliomas (OII or OIII) (1). Grade II oligodendrogliomas (OII) are rare and slow-growing tumors, and affected patients show long-term survival when treated with surgical resection at diagnosis, even though the majority eventually relapse (2). Presently accepted guidelines for treatment suggest that adjuvant radio- and/or chemotherapy be delayed until there is clinical evidence of disease progression in OII patients (3). However, it has been shown that their risk of relapse may be defined at an earlier stage (4). Traditionally, a low risk of recurrence among low-grade glioma patients has been related to clinical variables, such as age ( $\leq 40$ years) at diagnosis, seizures at presentation, absence of neurological deficits, a Karnofsky performance status of $\geq 70$, absence of enhancement at CT/MRI, a pre-operative tumor size of $\leq 5-6 \mathrm{~cm}$ and the tumor not crossing the midline (5). Moreover, a well-accepted molecular factor of prognostic significance is the allelic loss [loss of heterozygosity (LOH)] of chromosome 1p, together with 19q (6). Combined deletions of both arms were observed in up to $80 \%$ of ODG patients with prolonged survival (7-9), suggesting that these unstable chromosomal regions carry critical genes whose silencing may define their clinical history. Both the physical loss of a genetic trait and epigenetic silencing, via $\mathrm{CpG}$ island 
promoter methylation, may downregulate or suppress the expression of significant genes in cancer cells compared to normal ones. The epigenetic profiling of brain tumors has indeed significance as a prognostic index (10): e.g., the epigenetic silencing of $O^{6}$-methylguanine methyltransferase (MGMT, 10q26) correlates with responsiveness to alkylating agents and radiotherapy in glioblastoma (GBM, WHO grade IV) (11-13). The 19q region, frequently lost in ODG tumors, harbors putative tumor suppressor genes, such as the epithelial membrane protein 3 (EMP3,19q13.3) (14-19). The function of EMP3 remains unclear; however, its homology to peripheral myelin protein 22 (PMP22) suggests that the protein is implicated in cell cycle regulation and cell-to-cell interactions (17). The EMP3 promoter contains a $\mathrm{CpG}$ island, which is methylated in both high-grade astrocytoma and neuroblastoma brain tumors associated with poorer prognosis (14). Demethylating agents have been shown to restore EMP3 expression in neuroblastoma cell lines, with consequent lower in vitro colony formation and reduction of tumor growth in nude mice (14). A methylated EMP3 promoter was found by Li et al in a group of ODG samples with different histological classifications; however, no association between the EMP3 gene promoter methylation, the corresponding protein expression and $19 q$ deletion was found (20). However, Kunitz et al found a significant association between EMP3 promoter methylation and the allelic loss of $19 \mathrm{q}$, consistent with the reduced EMP3 mRNA expression (21). All these findings suggest that EMP3 methylation may occur in ODG together with LOH of chromosome $19 q$ (LOH 19q), although the clinical significance of their co-occurrence remains to be clarified.

We previously described a cohort of OII patients in whom LOH $19 \mathrm{q}$ was present in the subgroup at a higher risk of relapse (22). Given this preliminary evidence, in this study, we evaluated the EMP3 gene promoter in the same cohort of patients, to investigate whether $\mathrm{CpG}$ methylation of the residual allele promoter is consistent with the physical loss of the homologous allele promoter and whether a correlation can be established between EMP3 cyto- and epigenetic loss and a higher risk of relapse. In addition, we examined the $M G M T$ and cyclooxygenase 2 (COX2), an isozyme of prostaglandinendoperoxidase synthase 2 (1q25.2q25.3) gene promoter methylation in these patients. $M G M T$ is a gene of interest in high-grade gliomas, namely GBM, as the methylation of its promoter predicts chemosensitivity to alkylating agents; it is also under evaluation in low-grade gliomas $(11-13,23)$. The COX2 gene promoter methylation provides epigenetic information regarding genetic regions that are more stable than the $19 q$ arms, both in low- and high-grade gliomas. The methylation of the 3 gene promoters, EMP3, MGMT and $C O X 2$, was also evaluated in a small group of primary WHO grade IV gliomas, in order to validate a different epigenetic profile between low- and high-grade gliomas (21). A further characterization between these 2 subgroups was provided by isocitrate dehydrogenase 1 (IDH1) genotyping, as the $I D H 1$ mutation is rare in primary GBM but frequent in OII (24).

\section{Materials and methods}

Patients and tumor specimens. This study was carried out in a small homogeneous cohort of WHO grade II oligodendroglioma (OII) patients, an infrequent low-grade glioma subtype.
Study participants gave their informed consent to this study. The protocols were approved by the institutional ethics committee in accordance with the ethical standard of Declaration of Helsinki (1964). Samples from 23 patients were collected over a period of 10 years as previously described (22). The age and gender of patients are reported in Table I. Seventeen GBM (WHO grade IV) samples were collected from 15 patients ( 2 of which were relapses). There were 9 female patients (60\%); median age at the time of diagnosis was 62 years (range, 43-80) (Table II). Tumor samples were embedded in paraffin. All histological diagnoses were reviewed by 2 experienced neuropathologists (S.C. and L.R.).

Genomic DNA extraction. DNA extraction from the paraffinembedded tissue was performed using the standard procedure with phenol-chloroform from 5 slices ( $5-\mu \mathrm{m}$ thick). The paraffin was dissolved with xylene, and any remaining xylene was washed out with ethanol. After overnight protein digestion with proteinase $\mathrm{K}$, the DNA was separated from the organic phase with phenol-chloroform, precipitated with ethanol and resuspended in Tris-EDTA (TE) buffer.

Analysis of gene promoter methylation. The DNA was processed with sodium bisulfite, converting unmethylated cytosine to uracil, as previously described (11). Briefly, $1 \mu \mathrm{g}$ of DNA was denatured with sodium hydroxide and modified with sodium bisulfite. The DNA samples were then purified with a commercial kit (Wizard DNA Clean-Up System; A7280; Promega, Madison, WI, USA), and again treated with sodium hydroxide to complete the conversion to uracil. Finally, DNA was precipitated with ethanol and resuspended in $30 \mu \mathrm{l}$ of TE buffer. The methylation status of the genes of interest was determined by methylation-specific PCR (MSP), using 2 sets of primers (Table III), specific for either methylated or unmethylated DNA (25). The total volume for the MSP reaction was $15 \mu \mathrm{l}$, comprising $4 \mathrm{mM} \mathrm{MgCl} 2,0.5 \mathrm{mM}$ of each dNTP, $0.2 \mu \mathrm{M}$ of each primer, 0.5 unit of Hot Start DNA polymerase and $3 \mu \mathrm{l}$ of bisulfite-treated DNA. The methylation of the $M G M T$ and EMP3 gene promoters was spot-checked in selected GBM samples by bisulfite sequencing, cloning PCR products using the pGEM ${ }^{\circledR}$-T Easy Vector System (A1360, Promega). Selective positive clones were sequenced and products were aligned using the BioEdit sequence alignment editor.

Analysis of the IDH1 mutation. IDHI alterations of the mutational hotspot codon R132 were assessed by sequencing of PCR-amplified fragments. Primers used were 5'-ACCAAAT GGCACCATACGA-3' (forward) and 5'-TTCATACCTTGC TTAATGGGTGT-3' (reverse).

Data analysis. Disease progression-free interval (DPI) was defined as the time between surgery and either disease progression or the last follow-up examination. DPI curves were plotted using the Kaplan-Meier method with GraphPad Prism (Version 4.0, GraphPad Software, San Diego, CA, USA).

\section{Results}

Analysis of gene promoter methylation. Analysis of gene promoter methylation was performed via MSP, amplifying the 
Table I. Summary of OII patient personal data (age and gender), presence of loss of heterozygosity (LOH) of 1p and 19q, EMP3, $M G M T$ and $C O X 2$ promoter methylation status and $I D H 1$ genotyping.

\begin{tabular}{rrlcccccl}
\hline No. & Age & Gender & LOH lp & LOH 19q & EMP3 & MGMT & COX2 & IDHI \\
\hline 1 & 33 & Male & + & + & $\mathrm{M}$ & $\mathrm{M}$ & $\mathrm{U}$ & $\mathrm{R} 132 \mathrm{H}$ \\
2 & 50 & Male & + & + & $\mathrm{M}$ & $\mathrm{M}$ & $\mathrm{U}$ & wt \\
3 & 43 & Female & + & + & $\mathrm{M}$ & $\mathrm{M}$ & $\mathrm{U}$ & $\mathrm{R} 132 \mathrm{H}$ \\
4 & 35 & Male & + & + & $\mathrm{M}$ & $\mathrm{M}$ & $\mathrm{U}$ & $\mathrm{NI}$ \\
5 & 51 & Female & + & + & $\mathrm{M}$ & $\mathrm{NS}$ & $\mathrm{U}$ & $\mathrm{NI}$ \\
6 & 38 & Female & + & - & $\mathrm{M}$ & $\mathrm{NS}$ & $\mathrm{U}$ & $\mathrm{wt}$ \\
7 & 42 & Female & + & + & $\mathrm{M}$ & $\mathrm{M}$ & $\mathrm{NS}$ & $\mathrm{R} 132 \mathrm{H}$ \\
8 & 37 & Male & - & + & $\mathrm{M}$ & $\mathrm{M}$ & $\mathrm{U}$ & $\mathrm{wt}$ \\
9 & 59 & Female & + & + & $\mathrm{M}$ & $\mathrm{M}$ & $\mathrm{U}$ & $\mathrm{wt}$ \\
10 & 37 & Male & - & - & $\mathrm{M}$ & $\mathrm{M}$ & $\mathrm{U}$ & $\mathrm{R} 132 \mathrm{H}$ \\
11 & 33 & Female & + & - & $\mathrm{M}$ & $\mathrm{M}$ & $\mathrm{U}$ & $\mathrm{R} 132 \mathrm{H}$ \\
12 & 66 & Male & + & + & $\mathrm{M}$ & $\mathrm{NS}$ & $\mathrm{U}$ & $\mathrm{R} 132 \mathrm{H}$ \\
13 & 30 & Male & - & - & $\mathrm{M}$ & $\mathrm{M}$ & $\mathrm{U}$ & $\mathrm{R} 132 \mathrm{H}$ \\
14 & 70 & Male & + & + & $\mathrm{M}$ & $\mathrm{NS}$ & $\mathrm{U}$ & $\mathrm{NI}$ \\
15 & 42 & Female & + & + & $\mathrm{M}$ & $\mathrm{M}$ & $\mathrm{U}$ & $\mathrm{R} 132 \mathrm{H}$ \\
16 & 37 & Male & + & $\mathrm{NI}$ & $\mathrm{M}$ & $\mathrm{M}$ & $\mathrm{U}$ & $\mathrm{wt}$ \\
17 & 38 & Male & + & + & $\mathrm{M}$ & $\mathrm{M}$ & $\mathrm{U}$ & $\mathrm{R} 132 \mathrm{H}$ \\
18 & 37 & Female & - & + & $\mathrm{U}$ & $\mathrm{M}$ & $\mathrm{U}$ & $\mathrm{wt}$ \\
19 & 56 & Female & - & - & $\mathrm{M}$ & $\mathrm{M}$ & $\mathrm{U}$ & $\mathrm{R} 132 \mathrm{H}$ \\
20 & 69 & Male & + & + & $\mathrm{M}$ & $\mathrm{M}$ & $\mathrm{U}$ & $\mathrm{R} 132 \mathrm{H}$ \\
21 & 45 & Female & + & + & $\mathrm{M}$ & $\mathrm{M}$ & $\mathrm{U}$ & $\mathrm{NI}$ \\
22 & 28 & Female & + & - & $\mathrm{M}$ & $\mathrm{NS}$ & $\mathrm{U}$ & $\mathrm{R} 132 \mathrm{H}$ \\
23 & 39 & Female & + & + & $\mathrm{M}$ & $\mathrm{M}$ & $\mathrm{U}$ & $\mathrm{R} 132 \mathrm{G}$ \\
\hline
\end{tabular}

+, Loss of heterozygosity; -, heterozygosity; NI, not informative; M, methylated; U, unmethylated; NS, no PCR product; wt, wild-type.

Table II. Summary of GBM patient personal data (age and gender), presence of EMP3, MGMT and COX2 promoter methylation status and $I D H I$ genotyping.

\begin{tabular}{cclcccc}
\hline No. & Age & Gender & EMP3 & MGMT & COX2 & IDHI \\
\hline 1 & 56 & Female & $\mathrm{U}$ & $\mathrm{U}$ & $\mathrm{U}$ & $\mathrm{wt}$ \\
2 & 56 & Female & $\mathrm{U}$ & $\mathrm{U}$ & $\mathrm{U}$ & $\mathrm{wt}$ \\
3 & 73 & Male & $\mathrm{U}$ & $\mathrm{M}$ & $\mathrm{U}$ & $\mathrm{wt}$ \\
4 & 49 & Male & $\mathrm{U}$ & $\mathrm{U}$ & $\mathrm{U}$ & $\mathrm{wt}$ \\
5 & 43 & Female & $\mathrm{U}$ & $\mathrm{U}$ & $\mathrm{U}$ & $\mathrm{wt}$ \\
6 & 52 & Female & $\mathrm{U}$ & $\mathrm{M}$ & $\mathrm{U}$ & $\mathrm{NI}$ \\
7 & 68 & Female & $\mathrm{U}$ & $\mathrm{U}$ & $\mathrm{U}$ & $\mathrm{wt}$ \\
8 & 57 & Male & $\mathrm{U}$ & $\mathrm{M}$ & $\mathrm{U}$ & $\mathrm{wt}$ \\
9 & 59 & Female & $\mathrm{M}$ & $\mathrm{M}$ & $\mathrm{U}$ & $\mathrm{wt}$ \\
10 & 80 & Female & $\mathrm{U}$ & $\mathrm{M}$ & $\mathrm{U}$ & $\mathrm{wt}$ \\
11 & 74 & Female & $\mathrm{U}$ & $\mathrm{U}$ & $\mathrm{U}$ & $\mathrm{wt}$ \\
12 & 69 & Female & $\mathrm{U}$ & $\mathrm{U}$ & $\mathrm{U}$ & $\mathrm{wt}$ \\
13 & 62 & Male & $\mathrm{M}$ & $\mathrm{U}$ & $\mathrm{U}$ & $\mathrm{wt}$ \\
14 & 62 & Male & $\mathrm{U}$ & $\mathrm{U}$ & $\mathrm{U}$ & $\mathrm{wt}$ \\
15 & 74 & Male & $\mathrm{M}$ & $\mathrm{U}$ & $\mathrm{U}$ & $\mathrm{NI}$ \\
16 & 71 & Female & $\mathrm{U}$ & $\mathrm{U}$ & $\mathrm{U}$ & $\mathrm{NI}$ \\
17 & 55 & Male & $\mathrm{U}$ & $\mathrm{U}$ & $\mathrm{U}$ & $\mathrm{wt}$ \\
\hline
\end{tabular}

M, methylated; U, unmethylated; wt, wild-type; NI, not informative.
$5 '-\mathrm{CpG}$ island close to the transcription start site of each gene of interest (Fig. 1A and 1B). Among our 23 OII patients, the EMP3 gene promoter was methylated in 22 samples and unmethylated in 1 sample; $M G M T$ was methylated in 18 samples and no PCR product was scored in 5 cases; $C O X 2$ was unmethylated in 22 samples and no PCR product was detected in 1 sample (Fig. 2 and Table I).

As regards our 17 GBM patients, our results showed that the EMP3 gene promoter was methylated in 3 and unmethylated in 14 samples; $M G M T$ was methylated in 5 and unmethylated in 12 samples; COX2 was unmethylated in all the samples (Fig. 2 and Table II).

As a quality control strategy, selected GBM samples in which the MGMT and EMP3 gene promoter methylation was assayed by MSP were re-analyzed by bisulfite sequencing, confirming the MSP results (Fig. 1C).

Analysis of IDHI mutation. Analysis of the IDHI mutational hotspot codon R132 was evaluated in the OII and GBM patients. Among our 23 OII patients, 13 samples showed mutated IDHI. In 12 cases, a $\operatorname{Arg} \rightarrow$ His amino acid substitution (codon CGT $\rightarrow$ CAT change) was observed at residue 132; only 1 sample showed a $\mathrm{Arg} \rightarrow$ Gly mutation $(\mathrm{CGT} \rightarrow \mathrm{GGT}$ ). The wild-type genotype was observed in 6 samples. Four cases were not informative (Table I). 
Table III. Sequences of primers used for the promoter methylation analysis.

\begin{tabular}{|c|c|c|c|}
\hline Gene & Primer & Sequence $5^{\prime}-3^{\prime}$ & Annealing temperature $\left({ }^{\circ} \mathrm{C}\right)$ \\
\hline \multirow[t]{4}{*}{$M G M T$} & UM-F & TTTGTGTTTTGATGTTTGTAGGTTTTTGT & 62 \\
\hline & UM-R & ААСТССАСАСТСТТССАААААСААААСА & \\
\hline & M-F & TTTCGACGTTCGTAGGTTTTCGC & \\
\hline & $\mathrm{M}-\mathrm{R}$ & GCACTCTTCCGAAAACGAAACG & \\
\hline \multirow[t]{4}{*}{ EMP3 } & UM-F & GAAGAGATGTAGAAGGAGAGTGAGT & 62 \\
\hline & UM-R & СТТАТСССТСАСТСАААССТССАТА & \\
\hline & $\mathrm{M}-\mathrm{F}$ & GACGTAGAAGGAGAGCGAGC & \\
\hline & $\mathrm{M}-\mathrm{R}$ & CCTCGCTCGAACCTCCGTA & \\
\hline \multirow[t]{4}{*}{$\operatorname{COX} 2$} & UM-F & GAGAGGGGATTTTTTGTGTTTTT & 60 \\
\hline & UM-R & CCCAAACACTTCCAAAAACC & \\
\hline & $\mathrm{M}-\mathrm{F}$ & GAGGGGATTTTTTGCGTTTTC & \\
\hline & $\mathrm{M}-\mathrm{R}$ & CCGAACGCTTCCGAAAAC & \\
\hline \multirow[t]{2}{*}{$M G M T$} & BS-F & TTTTGATTAGGGGAGIGGT & 57 \\
\hline & BS-R & TCTATACCTTAATTTACC & \\
\hline \multirow[t]{2}{*}{ EMP3 } & BS-F & GGGAGTAAGAGAGAAGGAGGTTTAG & 60 \\
\hline & BS-R & TTAAAAAATCCCAACCCTAAATAAC & \\
\hline
\end{tabular}

F, forward; R, reverse; MSP primers: M, methylation-specific; UM, unmethylation-specific; BS, bisulfite sequencing primers.

In our 17 GBM patients, wild-type IDHI was found in 14 samples, none showed a mutated gene and 3 cases were not informative (Table II).

EMP3 gene promoter methylation vs. LOH 19q. 1p/19q allelic loss in OII samples was evaluated by microsatellite amplification as described in our previous study (22). LOH 1p was scored in 18 samples out of the total 23 (Table I). LOH 19q was present in 16 samples out of 22 ( 1 sample being not informative) (Table I). Concomitant LOH 1p/19q was observed in 14 out of 22 samples. Of the $16 \mathrm{LOH} 19 \mathrm{q}$ samples, 15 had the EMP3 gene promoter methylation, while only 1 exhibited the unmethylated EMP3 gene promoter (Table I). Moreover, the 6 samples with conserved 19q chromosome arms had a methylated EMP3 promoter (Table I).

LOH $19 q$ and DPI. DPI was evaluated in the 21 OII patients with methylated EMP3 promoter. Among them, 15 showed LOH 19q, while 6 showed conserved chromosome arms. Relapses were observed in $7 \mathrm{LOH} \mathrm{19q}$ patients and in 1 patient who retained both chromosome arms. Analysis of the DPI curves indicated a different risk of relapse depending on LOH 19q status. When this chromosome alteration was present, $55 \%$ of patients relapsed, compared to $17 \%$ when both chromosome arms were conserved (Fig. 3).

\section{Discussion}

We previously described a group of 23 OII patients evaluated for the presence of LOH 1p19q (22). OII is a neoplastic subclass of cancer with an overall more favorable outcome than other brain tumors. However, this outcome is heterogeneous and unpredictable at the individual level (26); thus, the policy to delay adjuvant therapy until clinical evidence of disease progression (3) may fail to treat some patients harboring aggressive tumors. Individuating features indicating the patient's risk of relapse at diagnosis would ensure a better clinical treatment. In our previous study (22), we identified a subgroup of patients with a shorter disease-free interval and LOH 19q, a cytogenetic alteration frequently observed in OII $(27,28)$ but not in GBM (29). We thus decided to evaluate in the same patients the methylation status of the EMP3 gene promoter located in the $19 q$ chromosome region (19q13.3), which has gained increasing interest as it is considered a candidate tumor suppressor gene for solid tumors (15), including brain tumors. The hypermethylated status of the EMP3 gene promoter in low-grade gliomas is known as a molecular feature distinguishing them from highgrade gliomas $(20,21)$. Thus, a reduced expression level of EMP3 resulting from the methylation of its gene promoter has been reported in OII (21), whereas the hyperexpression of EMP3 has been shown in GBM $(30,31)$. Further support of the critical role of EMP3 methylation in distinct glioma subtypes is provided by the observation of its different frequency in primary GBM (pGBM), vs. secondary GBM (sGBM) and grade II and III astrocytomas (AII and AIII) (21). The higher occurrence in the second group supports the idea that sGBM arises from the progression of anaplastic astrocytomas, while pGBM develops de novo via the dysregulation of different genetic pathways (21). This alternative methylation pattern of EMP3 in distinct glioma histotypes (GBM vs. OII) is consistent with the data obtained examining another important tumor suppressor gene, MGMT; its promoter methylation is currently a recognized prognostic marker of: i) disease progression in WHO grade III glioma (23); and ii) response to temozolomide in GBM (11-13). In our study, 


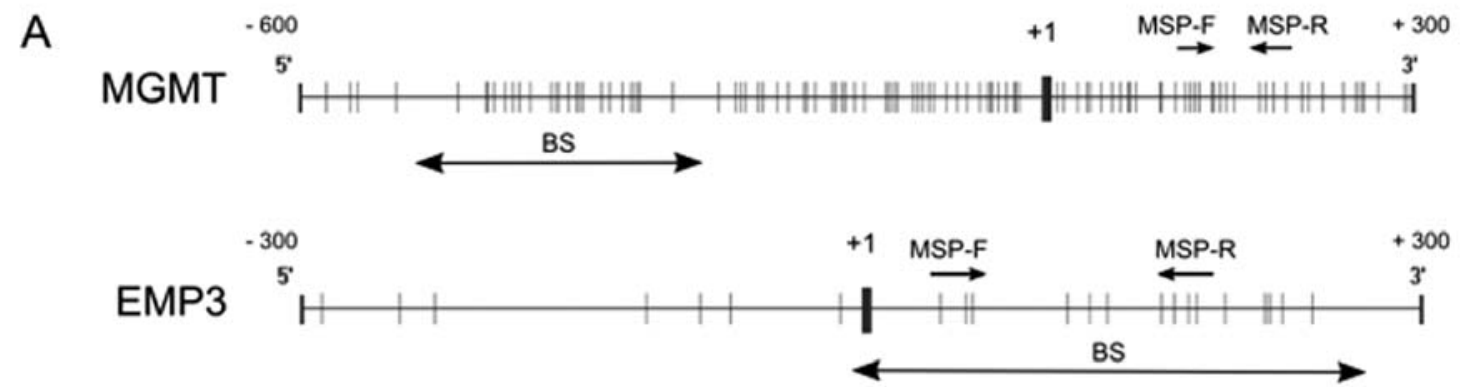

B

$$
\frac{21}{U M} \frac{22}{U M} \frac{23}{U M} \frac{N L}{U M} \frac{I V D}{M} \frac{\mathrm{H}_{2} \mathrm{O}}{U M}
$$

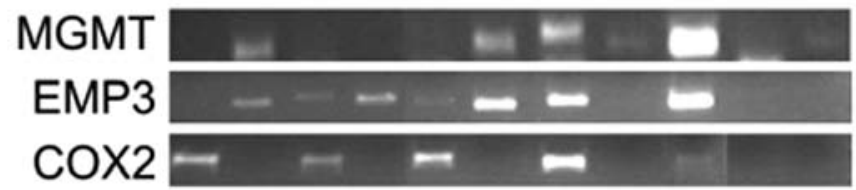

C
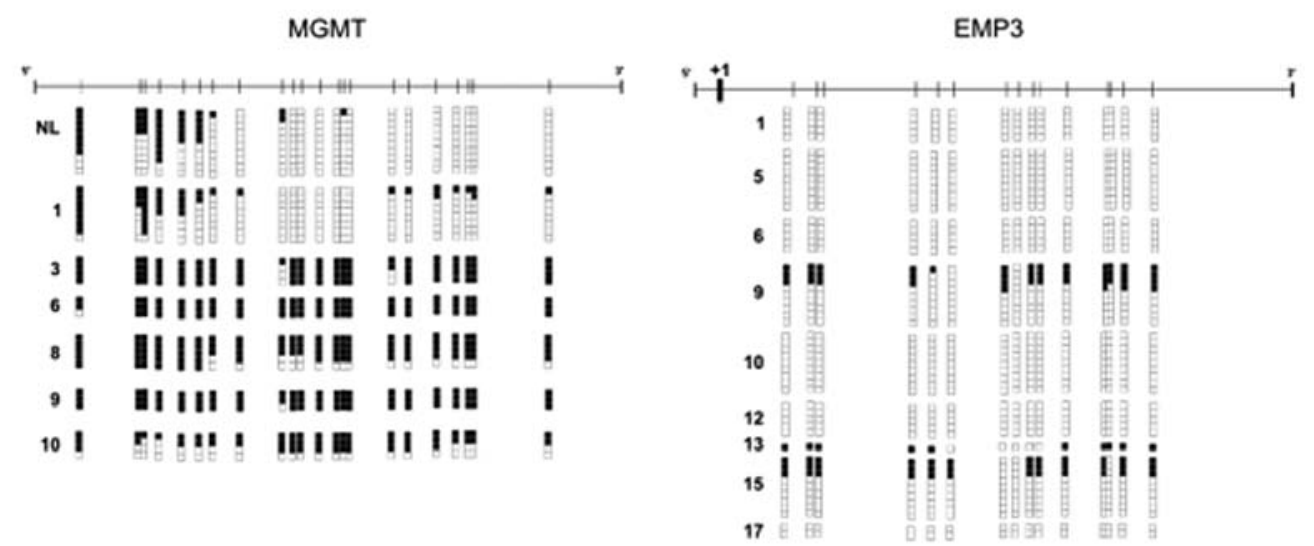

Figure 1. Promoter methylation analysis. (A) $M G M T$ and EMP3 CpG islands: vertical bars represent $\mathrm{CpG}$ sites; arrows indicate primer position for methylation-specific PCR (MSP) and amplification products of bisulfite sequencing (BS). (B) MSP results for MGMT, EMP3 and COX2 in representative samples from ODG patients. $\mathrm{U}$, unmethylation-specific reaction; $\mathrm{M}$, methylation-specific reaction; $\mathrm{NL}$, normal lymphocyte DNA; IVD, in vitro methylated DNA; $\mathrm{H}_{2} \mathrm{O}$, water control. (C) BS results for MGMT and EMP3 in selected GBM samples. Each square represents a clone, black when methylated or white when unmethylated.

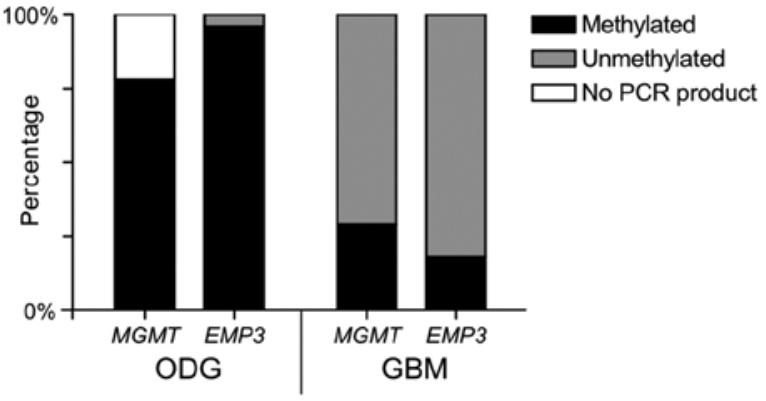

Figure 2. MGMT and EMP3 gene promoter methylation in ODG and GBM samples.

the methylation of the EMP3 gene promoter was detected in $96 \%$ of OII patients, but only in $18 \%$ of GBM samples (Fig. 2). All the informative OII samples showed the $M G M T$ gene promoter methylation, compared to the $29 \%$ observed in GBM (Fig. 2). Further differentiation between these 2 subgroups was provided by IDH1 genotyping: mutated IDH1 was present in approxi-

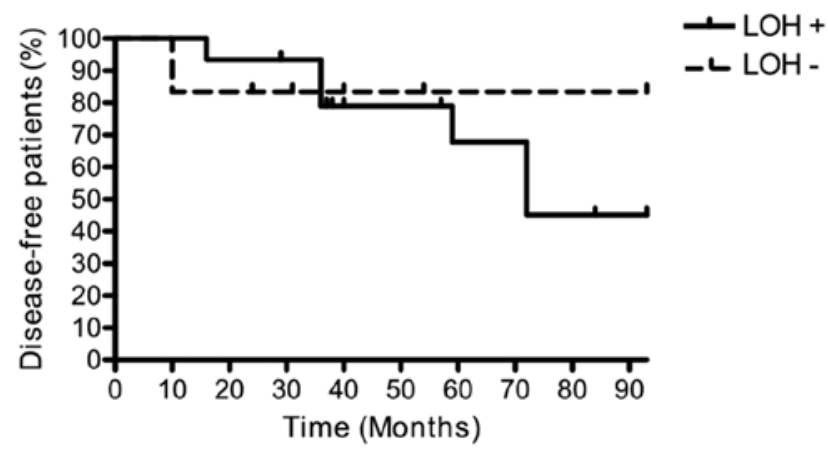

Figure 3. Disease progression-free interval in ODG patients with the EMP3 gene promoter methylation. $\mathrm{LOH}^{+}$, loss of heterozygosity of $19 \mathrm{q} ; \mathrm{LOH}^{-}$, conserved $19 \mathrm{q}$ chromosome arms.

mately $2 / 3$ of the informative OII samples but absent in all the GBM samples; these results are in agreement with those from previous studies (24). The unmethylated status of the COX2 
gene promoter in both low- and high-grade gliomas confirms the stability of the genetic region 1q, conserved in both these tumor types, and supports a correlation between chromosome instability and $\mathrm{CpG}$ island methylation.

Given the findings in the literature reporting a reduced expression level of EMP3 resulting from the methylation of its gene promoter $(21,32)$, we thus assumed that in OII patients with LOH 19q, methylation of the gene copy located on the residual chromosome arm would imply its silencing, with an unfavorable outcome. Further support of this hypothesis is provided by the report of a more aggressive tumor phenotype associated with EMP3 promoter methylation in neuroblastoma patients (14), and by the finding that the re-expression of EMP3, induced by demethylating agents, is associated with lower tumorigenicity in neuroblastoma cell lines (demonstrated by lower in vitro colony formation and reduced tumor size of xenografts) (14). Our results indicate that the EMP3 gene promoter methylation is a hallmark in OII patients and that when this event occurs in the presence of LOH 19q, a complete (cyto- and epigenetic) functional loss of both EMP3 alleles occurs. Its putative role as a tumor suppressor gene fits well with our findings regarding DPI: a higher risk of relapse was observed in patients with LOH 19q/EMP3 methylation (55\%) vs. the patients who, although harboring methylated EMP3, had both $19 \mathrm{q}$ chromosome arms conserved (17\%) (Fig. 3). The small sample size, collected over a 10 -year period at our clinical institution, due to the low frequency of this neoplastic disease, limits the statistical power of this result; nevertheless, our observation discloses a potential molecular explanation for the higher risk of relapse of OII patients with deleted 19q.

In conclusion, the results from our study on OII patients highlight the fact that $\mathrm{LOH} 19 \mathrm{q}$ determines the complete loss of EMP3 function, as the conserved allele is frequently hypermethylated, and this may represent the molecular basis of the higher risk of relapse in this subgroup of OII patients. Testing this hypothesis in a larger number of patients is of clinical relevance to highlight the presence of EMP3 gene promoter methylation together with $\mathrm{LOH} 19 \mathrm{q}$ as an indication for treatment $a b$ initio with adjuvant therapy in order to improve the overall survival of these patients.

\section{Aknowledgements}

We are grateful to Ms. Kristina Mayberry for the careful critical editing of the manuscript.

\section{References}

1. Louis DN, Ohgaki H, Wiestler OD, Cavenee WK, Burger PC, Jouvet A, et al: The 2007 WHO classification of tumours of the central nervous system. Acta Neuropathol 114: 97-109, 2007.

2. El-Hateer H, Souhami L, Roberge D, Maestro RD, Leblanc R, Eldebawy, et al: Low-grade oligodendroglioma: an indolent but incurable disease? J Neurosurg 111: 265-271, 2009.

3. Mason WP: Oligodendroglioma. Curr Treat Options Neurol 7: 305-314, 2005

4. Shaw EG, Berkey B, Coons SW, Bullard D, Brachman D, Buckner JC, et al: Recurrence following neurosurgeon-determined gross-total resection of adult supratentorial low-grade glioma: results of a prospective clinical trial. J Neurosurg 109: 835-841, 2008
5. Pignatti F, van den Bent M, Curran D, Debruyne C, Sylvester R, Therasse P, Afra D, Cornu P, Bolla M, Vecht C and Karim AB; European Organization for Research and Treatment of Cancer Brain Tumor Cooperative Group; European Organization for Research and Treatment of Cancer Radiotherapy Cooperative Group: Prognostic factors for survival in adult patients with cerebral low-grade glioma. J Clin Oncol 20: 2076-2084, 2002.

6. Jenkins RB, Blair H, Ballman KV, Giannini C, Arusell RM, Law M, et al: A t $(1 ; 19)(\mathrm{q} 10 ; \mathrm{p} 10)$ mediates the combined deletions of $1 \mathrm{p}$ and $19 \mathrm{q}$ and predicts a better prognosis of patients with oligodendroglioma. Cancer Res 66: 9852-9861, 2006.

7. Felsberg J, Erkwoh A, Sabel MC, Kirsch L, Fimmers R, Blaschke B, et al: Oligodendroglial tumours: refinement of candidate regions on chromosome arm $1 \mathrm{p}$ and correlation of 1p/19q status with survival. Brain Pathol 14: 121-130, 2004.

8. Okamoto Y, Di Patre PL, Burkhard C, Horstmann S, Jourde B, Fahey M, et al: Population-based study on incidence, survival rates, and genetic alterations of low-grade diffuse astrocytomas and oligodendrogliomas. Acta Neuropathol 108: 49-56, 2004.

9. van den Bent MJ, Looijenga LH, Langenberg K, Dinjens W, Graveland W, Uytdewilligen L, et al: Chromosomal anomalies in oligodendroglial tumours are correlated with clinical features. Cancer 97: 1276-1284, 2003.

10. Natsume A, Kondo Y, Ito M, Motomura K, Wakabayashi T and Yoshida J: Epigenetic aberrations and therapeutic implications in gliomas. Cancer Sci 101: 1331-1336, 2010.

11. Esteller M, Hamilton SR, Burger PC, Baylin SB and Herman JG: Inactivation of the DNA repair gene $\mathrm{O}^{6}$-methylguanine-DNA methyltransferase by promoter hypermethylation is a common event in primary human neoplasia. Cancer Res 59: 793-797, 1999.

12. Esteller M, Garcia-Foncillas J, Andion E, Goodman SN, Hidalgo OF, Vanaclocha V, et al: Inactivation of the DNA-repair gene MGMT and the clinical response of gliomas to alkylating agents. N Engl J Med 343: 1350-1354, 2000.

13. Hegi ME, Diserens AC, Gorlia T, Hamou MF, de Tribolet N, Weller M, et al: MGMT gene silencing and benefit from temozolomide in glioblastoma. N Engl J Med 352: 997-1003, 2005.

14. Alaminos M, Dávalos V, Ropero S, Setién F, Paz MF, Herranz M, et al: EMP3, a myelin-related gene located in the critical 19 q13.3 region, is epigenetically silenced and exhibits features of a candidate tumour suppressor in glioma and neuroblastoma. Cancer Res 65: 2565-2571, 2005.

15. Fumoto S, Tanimoto K, Hiyama E, Noguchi T, Nishiyama M and Hiyama K: EMP3 as a candidate tumor suppressor gene for solid tumors. Expert Opin Ther Targets 13: 811-822, 2009.

16. Qu M, Jiao H, Zhao J, Ren ZP, Smits A, Kere J and Nistér M: Molecular genetic and epigenetic analysis of NCX2/SLC8A2 at 19q13.3 in human gliomas. Neuropathol Appl Neurobiol 36: 198-210, 2010.

17. Taylor V and Suter U: Epithelial membrane protein-2 and epithelial membrane protein-3: two novel members of the peripheral myelin protein 22 gene family. Gene 175: 115-120, 1996.

18. Tews B, Felsberg J, Hartmann C, Kunitz A, Hahn M, Toedt G, et al: Identification of novel oligodendroglioma-associated candidate tumour suppressor genes in $1 \mathrm{p} 36$ and $19 \mathrm{q} 13$ using microarray-based expression profiling. Int J Cancer 119: 792-800, 2006.

19. Yim JH, Kim YJ, Ko JH, Cho YE, Kim SM, Kim JY, et al: The putative tumour suppressor gene GLTSCR2 induces PTENmodulated cell death. Cell Death Differ 14: 1872-1879, 2007.

20. Li KK, Pang JC, Chung NY, Ng YL, Chan NH, Zhou L, et al: EMP3 overexpression is associated with oligodendroglial tumours retaining chromosome arms $1 \mathrm{p}$ and $19 \mathrm{q}$. Int $\mathrm{J}$ Cancer 120: 947-950, 2007.

21. Kunitz A, Wolter M, van den Boom J, Felsberg J, Tews B, Hahn M, et al: DNA hypermethylation and aberrant expression of the EMP3 gene at 19q13.3 in human gliomas. Brain Pathol 17: 363-370, 2007.

22. Molinari C, Iorio P, Medri L, Ballardini M, Guiducci G, Cremonini AM, et al: Chromosome $1 \mathrm{p}$ and $19 \mathrm{q}$ evaluation in low-grade oligodendrogliomas: A descriptive study. Int J Mol Med 25: 145-151, 2010.

23. Brandes AA, Tosoni A, Cavallo G, Reni M, Franceschi E, Bonaldi L, et al: Correlations between $\mathrm{O}^{6}$-methylguanine DNA methyltransferase promoter methylation status, $1 \mathrm{p}$ and $19 \mathrm{q}$ deletions, and response to temozolomide in anaplastic and recurrent oligodendroglioma: a prospective GICNO study. J Clin Oncol 24: 4746-4753, 2006 
24. Ichimura K, Pearson DM, Kocialkowski S, Bäcklund LM, Chan R, Jones DT and Collins VP: IDH1 mutations are present in the majority of common adult gliomas but are rare in primary glioblastomas. Neuro Oncol 11: 341-347, 2009.

25. Herman JG, Graff JR, Myöhänen S, Nelkin BD and Baylin SB: Methylation-specific PCR: a novel PCR assay for methylation status of CpG islands. Proc Natl Acad Sci USA 93: 9821-9826, 1996.

26. Giannini C, Burger PC, Berkey BA, Cairncross JG, Jenkins RB, Mehta M, et al: Anaplastic oligodendroglial tumours: refining the correlation among histopathology, $1 \mathrm{p} 19 \mathrm{q}$ deletion and clinical outcome in Intergroup Radiation Therapy Oncology Group Trial 9402. Brain Pathol 18: 360-369, 2008.

27. Bello MJ, Leone PE, Vaquero J, de Campos JM, Kusak ME, Sarasa JL, et al: Allelic loss at $1 \mathrm{p}$ and $19 \mathrm{q}$ frequently occurs in association and may represent early oncogenic events in oligodendroglial tumours. Int J Cancer 64: 207-210, 1995.

28. Smith JS, Alderete B, Minn Y, Borell TJ, Perry A, Mohapatra G, et al: Localization of common deletion regions on $1 \mathrm{p}$ and $19 \mathrm{q}$ in human gliomas and their association with histological subtype. Oncogene 18: 4144-4152, 1999.
29. Kaneshiro D, Kobayashi T, Chao ST, Suh J and Prayson RA: Chromosome $1 \mathrm{p}$ and $19 \mathrm{q}$ deletions in glioblastoma multiforme. Appl Immunohistochem Mol Morphol 17: 512-516, 2009.

30. Nigro JM, Misra A, Zhang L, Smirnov I, Colman H, Griffin C, et al: Integrated array-comparative genomic hybridization and expression array profiles identify clinically relevant molecular subtypes of glioblastoma. Cancer Res 65: 1678-1686, 2005.

31. Ruano Y, Mollejo M, Ribalta T, Fiaño C, Camacho FI, Gómez E, et al: Identification of novel candidate target genes in amplicons of Glioblastoma multiforme tumors detected by expression and CGH microarray profiling. Mol Cancer 5: 39, 2006.

32. Fumoto S, Hiyama K, Tanimoto K, Noguchi T, Hihara J, Hiyama E, et al: EMP3 as a tumor suppressor gene for esophageal squamous cell carcinoma. Cancer Lett 274: 25-32, 2009. 